\title{
Welcome to the New Journal
}

\author{
Stephen Billett
}

Published online: 9 January 2008

(C) Springer Science + Business Media B.V. 2007

Welcome to Vocations and Learning: Studies in vocational and professional learning a truly interdisciplinary and independent journal that seeks to inform the fields of vocational and professional education.

This journal focuses on two related concepts: Vocations, those practices that have personal and/or cultural significance, and learning, the processes of individual change and the remaking and transformation of those practices that arise through that learning. The ambition for Vocations and Learning is to make significant contributions to scholarship about vocations and learning, particularly as they apply to the fields of vocational and professional education, and to impact upon theory, policy and practice in these fields.

The journal has a particular emphasis on those vocational practices that comprise paid occupations, their enactment and learning. This includes considerations of what constitutes work, occupations, working life and how individuals learn about working life, particular occupations and secure the capacities required for engaging in their chosen vocational practice, and the ongoing development of those capacities across their working lives, including transitions within and across different kinds of occupational practice. These considerations seem equally pertinent to the range of paid occupations, regardless of their being labelled as 'trade', 'skilled', 'professional', 'para-professional' work. Qualitatively, there seems to be little difference in the qualities of forms of knowledge required to participate in this range of occupations. Consequently, for these reasons, the contributions to and deliberations within this journal are held to be equally applicable to fields of practice labelled vocational and professional education.

However, considerations of vocations and learning also extend to those vocational practices that are not paid, yet which constitute activities that are personally and/or culturally significant. These kinds of vocations reflect many of the qualities and

\footnotetext{
S. Billett $(\square)$

School of Education and Professional Studies (Brisbane-Logan), Griffith University, Nathan 4111, Australia

e-mail: s.billett@griffith.edu.au
} 
characteristics of paid occupational activities, but are not remunerated (e.g. parenting), or that might be undertaken because they are not remunerated (e.g. charity or community work, post-employment activities) yet, nevertheless, have particular cultural or personal pertinence for those who learn and practice them. However, most contributions to this journal will comprise considerations of and deliberations about adults and adolescents' vocations and learning, as other journals provide specialised platforms for understanding further children's learning and development. The priority here is to focus on professional and vocational learning beyond the compulsory years of schooling.

Indeed, the field of vocational education is long-standing, expansive and diverse in its manifestation across and sometimes within countries. It includes the highly developed stand-alone vocational education systems that exist in many in countries such as England, Scotland, Germany, France, Switzerland, Malaysia, Thailand, Austria, Norway, Finland, Australia, Canada, China, Russia and Brazil. These are often quite separate and distinct from both the schooling and higher education provisions, and are sometimes referred to as tertiary education. By differing degree they tend to favour the development of specific vocational skills usually for those occupations that are warranted not to require a university-based preparation (i.e. occupations described as skilled and semi-professional). Moreover, even where there is a separate vocational education sector, in some of these countries (e.g. in Australia) the provision of vocational education is now being extended into high schools to address governmental concerns about youth employment, school-to-work transitions and to provide vocational educational provisions as part of the schooling curricula.

Elsewhere, vocational education is seen mainly as an educational provision within senior schooling or post compulsory institutions whose educational mandate is primarily about general educational albeit with a vocational option or orientation (e.g. USA, Taiwan). This kind of provision is often less occupational-specific and is of the sometimes labelled technical education, thereby emphasising an area of more general education curriculum. So here, the associations with schooling and more general educational purposes may be stronger than in stand-alone vocational education institutions.

Other countries are seeking to establish vocational education systems (e.g. Botswana, Maldives Laos, Vietnam) that are commensurate with their resources and national goals. However, they are often also being pressed by external agencies to conform to European institutional models, such as the German dual system. Yet, for these developing provisions of vocational education, it is necessary to find approaches to and institutions that can support this learning and in ways commensurate with their circumstances and goals. These distinct systems of vocational education have arisen over time and been shaped by the particular sets of national and regional factors. While they may share the same general goals, the forms of the purposes and processes, and their standing in the community can be quite distinct. In this way, there are a range of issues about purposes and processes that are required to be addressed often within the constraints of strong institutional and governmental imperatives.

Professional education is usually that initially enacted through courses within university programs and then continues in different forms throughout the working Springer 
lives of professions. While university education provisions have long provided specific preparation for prestigious occupations (e.g. medicine, law, clergy etc), the scope of and emphasis on occupationally-specific course provisions has expanded in recent decades to include that for teachers, nurses, journalists, social workers. However, and like vocational education, there are growing demands for these courses to be more effective in immediately meeting the complex needs of professional practice and effective student transition to employment in that practice. Hence, the preparation for professional learning has come under particular scrutiny, and is gradually embracing practice-based approaches to curriculum and pedagogy in the academy and in workplace settings. These include effort to integrate experiences from both kinds of settings. Equally, the challenges associated with maintaining the currency of occupational practice throughout working life are also now a central concern within the professions. The nature and focus of these kinds of developments are questioned in both fields as the character of both the occupational practice and the educational provision for that practice are facing new challenges. Indeed, there is global interest in maintaining and developing further workplace competence in professional occupations as these workers become a growing component of national workforces and as their work requirements become subject to both change and scrutiny.

Overall, it seems that interest in vocational and professional education is growing in a growing number of countries who are now being required to compete in the global economy, and in ways that make workers' skills and adaptability a prime consideration. All this indicates a growing need to be more informed about how vocational learning proceeds and can be best secured. Pragmatically, these interests are driven by economic imperatives arising from increasingly globalised economy and the demand for all nations to engage with and compete effectively in that economy. Consequently, the global requirement for countries' workforces to be oriented towards and effective in the generation of exportable goods and services and also to compete effectively against imported goods and services, stand as important national economic and societal goals.

Beyond these kinds of governmental and immediate social imperatives that are shaping the purposes, processes and preferred outcomes of professional and vocational education, it is necessary and appropriate to place learners centrally within these discussions. What constitutes vocations and their enactment necessarily individuals who practise them. Moreover, the process of learning cannot be understood without some consideration of the role which individuals play in the construction of knowledge. Given the central role of occupational identity in guiding and directing work life trajectories, the requirements to learn for vocations and maintain workplace competence throughout working life, there are important personal imperatives that need to be understood further and promoted. These extend to the role that vocational and professional education plays in personal as well as social emancipation and development. So, in these ways, the exercise of efforts to maximise this learning needs and secure both societal and personal goals needs to be supported by scholarship that informs both policy and practice in these countries.

Further, the settings through which learning for vocations occurs extend beyond those specifically established for these purposes (i.e. schools, colleges, universities). For instance, in most countries, the provision of vocational education includes 
workplace-based arrangements and also in those where highly specific skills (e.g. aircraft mechanics and flight crewing) and patented procedures (e.g. software applications) are developed. So, outside of educational institutions, learning through and for vocations proceeds in both small and large enterprises in all countries, for instance, through everyday work activities and intentional learning.

There is also the ongoing development throughout working life in all forms of occupations which has becomes a feature of contemporary working life, and likely largely occurs through individuals' work practice. This ongoing learning is now seen as an urgent imperative by employers, governments and industry spokespersons, and for individuals themselves. Yet, its provision for workers of different ages, skill and qualification levels and backgrounds represents key challenges for all these interested parties. Consequently, the provision of vocational learning comprises a significant educational project, albeit manifested in different ways across countries, regions and cultures. Indeed, many of the same issues of and goals for practice, learning, process of learning and assessment, such as those concerned with integrating different learning experiences in the workplace and educational settings also present. In this way, similar issues are to be addressed in both professional and vocational education. These include how pedagogy and curriculum should be conceptualised and enacted. Indeed, much the educational purposes, focuses and approaches are similar across these two fields. Hence, there is a convergence here in the focus, application and direction of scholarly work across these two fields of education.

Yet, while common, the range of issues and their complexity suggests that a broad platform of theoretical perspectives and contributions will be required to address these issues and provide a more comprehensive understanding about the project of vocational and professional education. Indeed, the nature of vocations and learning requires the engagement of and likely interaction across a range of disciplinary and theoretical contributions. So, although the primary focuses of this journal is on vocations 'and' learning, this does not imply a privileging of psychological perspectives. Instead, the purposes, processes and appraisals of vocations and learning, considerations of pedagogic and curriculum concepts practices, epistemologies and policy frames are to be expressly informed by a diverse range of disciplines. Already, disciplines such as anthropology have done much to assist the understanding of the origins of vocational practices and how they are learnt. Historical studies inform about traditions of the social privileging of occupations and the means by which individuals have learnt their vocational practice. Economics have provided understandings about the outcomes of participation in vocational learning and also ways in which the support for the learning is distributed across the community. Also, while philosophic studies inform about the different purposes of occupations and the goals for education associated with those occupations, they also provide premises from which to appraise what occurs in educational institutions and also what might be expected of those who learn vocational practice. Not surprisingly, sociology informs about the purposes, outcomes and the distribution of opportunities for participation in vocational and professional learning. Yet, it also informs a range of considerations about how the contributions of learning environments albeit educational institutions or other kinds of settings shape the learning of vocational practice. It is possible to continue with this list. Yet, in all and, therefore, the journal welcomes diverse perspective and multi-disciplinary accounts of vocations and learning.

Springer 
Indeed, the need for a truly independent, international and multi-disciplinary journal able to provide a platform for such perspectives, in part, motivated the establishment of Vocations and Learning. Therefore, given the existing and now growing importance of the fields of vocational and professional education, and its potential for further growth, it is anticipated that this journal will be well placed to inform theorising about, and policy and practice in these important fields of education. Consistent with this impetus, the key purpose of this journal is to advance the understanding of and practices that support the understanding of both vocations and learning as sets of concerns within the fields of vocational and professional education. Indeed, the impetus for its establishment is associated with concerns within a number of research communities that the fields of vocational and professional learning are not well represented by journals whose scholarly standing, disciplinary scope and international contributions do justice to these important educational sectors. Also, as educational sectors whose profiles and practices are much shaped by governmental and other agencies and institution's interests, the journal's editorial independence is held as an essential quality.

There are other imperatives and prospects that demonstrate the need for the establishment of Vocations and Learning. There is a growing need for a journal that can provide a vehicle for the increasing number of researchers in the fields of vocational and professional education who are being asked to present their work in English language publications. Scholars from Norwegian, Denmark, Finnish, Dutch and Swedish universities all report the growing imperative for them to publish their research in highly-ranked English-language journals, rather than domestic journals and in their native language. They are being pressed by their governments and institutions to make their work more widely available and through top tier journals. As research on learning for work and through working life has always been strong in the countries within northern Europe in particular, the need for an independent and high-quality, peer-reviewed English language journal to which researchers from these countries can submit their work has become a priority. This move also offers the prospect of scholarship that has previously only been published in other languages now being made available to English language audiences. In this way, the research traditions, conceptual heritage and preferred approaches of non-English language countries can hopefully be made available to a wider audience. In particular, it would be useful if some of the, earlier contributions about vocational and professional from French and German language researchers could now be made available through this journal. Importantly, this situation provides the opportunity for work which has been inaccessible to English language only audiences to be engaged by a broader range of ideas and different theoretical and methodological traditions.

It is these kinds of prospects that the readership of the journal can look forward to and for the scholarly community to advance its contributions through. In this way, the editorial team welcomes contributions to this journal and appreciate the contributions of those who submit their work for review. In addition, we acknowledge the contribution of those who take the time and use their scholarship to review these submissions anonymously. The work of reviewers is central to the quality of the journal and yet their contributions remain largely unrecognized. We thank them here in advance and will recognize their contribution in each year's final issue. 